\title{
Lobar pressure-volume characteristics of excised human lungs
}

\author{
N BEREND, C SKOOG, AND W M THURLBECK \\ From the Department of Pathology, University of Manitoba, Winnipeg, Manitoba, Canada
}

\begin{abstract}
The pressure-volume $(\mathrm{P}-\mathrm{V})$ characteristics were investigated in 14 excised left human lungs and their individual lobes. Comparison of the upper and lower lobar P-V curves of the emphysema-free and emphysematous lungs showed no significant difference when plotted as per cent lobar volume at a transpulmonary pressure $\left(P_{L}\right)$ of $30 \mathrm{~cm} \mathrm{H}_{2} \mathrm{O}\left(\mathrm{V}_{30}\right)$. However, when in the $=$ emphysematous lungs the more severely involved lobes were compared with the less severely involved lobes, significant differences in the $\mathrm{PL}_{\mathrm{L}} 60-90 \% \mathrm{~V}_{30}$ were found, the more severely을 involved lungs exhibiting a higher PL. The mean linear intercepts were identical in the upper and lower lobes of the emphysema-free lungs indicating equal distension and validating ex- $\infty$ pression of the $\mathrm{P}-\mathrm{V}$ data as per cent $\mathrm{V}_{30}$. However, in the emphysematous lungs, in which the upper lobes were more severely involved, the linear intercepts tended to be larger in the upper lobes and the ratio of upper to lower lobe $V_{30}$ tended to be larger than in the emphysema-free lungs. Thus, in the emphysematous lungs, comparison of the lobar P-V curves expressed as per cent $\mathrm{V}_{30}$ may not be valid.
\end{abstract}

Pressure-volume (P-V) characteristics of excised lungs and their individual lobes have been studied in a number of different animals with varying results. Frank ${ }^{1}$ and Faridy et $a l,{ }^{2}$ in a large number of dog lungs (31 and 104, respectively) demonstrated small but definite differences in the $\mathbf{P}-\mathrm{V}$ behaviour of upper and lower lobes. Similar findings have been obtained in rabbits. ${ }^{3}$ In monkeys, however, no significant difference in lobar $\mathbf{P}-\mathrm{V}$ characteristics were demonstrated by Paré et al. ${ }^{4}$ There is only one study comparing the elastic properties of upper and lower lobes in excised human lungs, ${ }^{5}$ and it showed significant differences with a shift to the left of the upper lobe $\mathrm{P}-\mathrm{V}$ curve compared to that of the lower.

In the present study, P-V curves were obtained from 14 excised human left lungs and their individual lobes in order to compare lobar elastic properties.

\section{Methods}

Left lungs were obtained from 14 non-hospitalised subjects who died suddenly from non-respiratory

Address for reprint requests: Dr N Berend, Department of Medicine, National Jewish Hospital and Research Centre, 3800 East Colfax Avenue, Denver, Colorado 80206, USA. causes. The lungs were selected for the presence $\frac{3}{5}$ of a complete interlobar fissure or the absence of interlobar ventilation tested as follows. The pulmonary vasculature was ligated, the main bronchio cannulated, and the lungs degassed. Either the upper or lower lobe bronchi were then clamped $\frac{0}{5}$ and the lungs inflated to a transpulmonary press - . ure $(\mathrm{PL})$ of $30 \mathrm{~cm} \mathrm{H} \mathrm{H}_{2} \mathrm{O}(3 \mathrm{kPa})$. When, on close visual inspection, no change in volume occurred in the clamped degassed lobe, the lung was deemed $\mathrm{O}$ suitable for the study. The procedure was then $>$ repeated with the other lobe. Small pleural leaks were repaired by ligature or Krazy Glue (Krazy O Glue Inc, Chicago, Illinois).

The degassed lungs were placed on a moist tray $\tilde{O}^{-}$ in a volume displacement plethysmograph and inflated with a blower to a $\mathrm{PL}$ of $30 \mathrm{cmH}_{2} \mathrm{O}$ ( $3 \mathrm{kPa}$ ), measured with a Validyne DP15 pressureo transducer. Volume change was measured with a Krogh spirometer. On the third deflation, $\mathrm{PL}_{\mathrm{L}}$ was $^{+}$ reduced to $0 \mathrm{cmH}_{2} \mathrm{O}$ in small decrements such that about $25 \mathrm{P}-\mathrm{V}$ points were recorded. All $\stackrel{\mathrm{C}}{\mathrm{C}}$

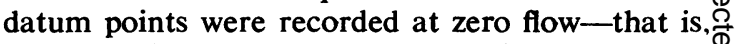
after waiting up to 30 seconds for volume to stabilise at each new pressure. The manoeuvre? was then repeated to check for reproducibility. 8 The lungs were removed from the plethysmo- 
graph, degassed again, and the upper or lower lobe bronchus clamped in random order. Pressurevolume curves were obtained as described above on upper and lower lobes and then again on the whole left lungs for comparison with the original curves to make sure that no changes had occurred during the procedure. In two lungs, $\mathrm{P}-\mathrm{V}$ curves could only be obtained on the whole lung and one lobe since the other lobe developed irreparable leaks. The intact lobe could, therefore, not be used for analysis by paired Student's $t$ test. Since not all lungs had complete interlobar fissures (those that had small connections presumably had a septum separating the lobes), no attempt was made to separate the lobes physically for fear of creating leaks.

The lobar and whole lung $\mathrm{P}-\mathrm{V}$ curves were then replotted with the volume axis expressed as volume per cent maximal volume, defined as the volume at a $\mathrm{PL}$ of $30 \mathrm{cmH}_{2} \mathrm{O}\left(\mathrm{V}_{30}\right)$. The volume at a PL of $0 \mathrm{cmH}_{2} \mathrm{O}$ was designated $\mathrm{V}_{0}$ and expressed as a percent of the $\mathrm{V}_{30}\left(\mathrm{~V}_{0} \% \mathrm{~V}_{30}\right)$.

The lungs were then inflated with $10 \%$ neutral buffered formalin at a constant $\mathrm{PL}$ of $25 \mathrm{cmH}_{2} \mathrm{O}$ $(2.5 \mathrm{kPa})$ for 72 hours. The lungs were sliced and paper-mounted whole lung sections prepared. These were used to grade the degree of emphysema on an arbitrary scale of $0-100 .^{6}$ Three blocks were taken at random from the lateral slices of each of the upper and lower lobes and $5 \mu \mathrm{m}$ slides prepared, stained with haematoxylin and eosin. The average interalveolar wall distance (mean linear intercept, Lm) was measured using standard methods. ${ }^{7}$ The shrinkage during processing was determined and the $\mathrm{Lm}$ appropriately corrected.

The $\mathrm{Lm}$ of the upper and lower lobes was also determined on a further 26 emphysema-free lungs, fixed and treated as described above.

The significance of differences between pairs of observations was tested by Student's $t$ test.

\section{Results}

The ages, sex, and emphysema grades of 14 lungs are shown in table 1 . The mean $\mathrm{P}-\mathrm{V}$ curves of all the lungs are plotted in fig 1 . There were no significant differences in PL between the upper and lower lobes at any lung volume. However, the PL for the whole lungs tended to be a little higher than for the individual lobes at all lung volumes and this reached statistical significance for the $\mathrm{PL}$ at $50 \% \mathrm{~V}_{30}$. The upper and lower lobe $\mathrm{P}-\mathrm{V}$ curves of the non-emphysematous and emphysematous lungs are compared in figs 2 and 3, respectively. For both non-emphysematous and
Table 1 Age, sex, and degree of emphysema of the lungs studied

\begin{tabular}{rlll}
\hline & Age & Sex & Emphysemagrade \\
\hline 1 & 48 & F & 20 \\
2 & 16 & M & 0 \\
3 & 54 & M & 0 \\
4 & 22 & M & 0 \\
5 & 52 & M & 15 \\
6 & 60 & F & 15 \\
7 & 70 & F & 5 \\
8 & 48 & M & 0 \\
9 & 70 & M & 20 \\
10 & 44 & M & 5 \\
11 & 55 & M & 15 \\
12 & 86 & F & 0 \\
13 & 51 & F & 10 \\
14 & 87 & M & 10 \\
\hline
\end{tabular}

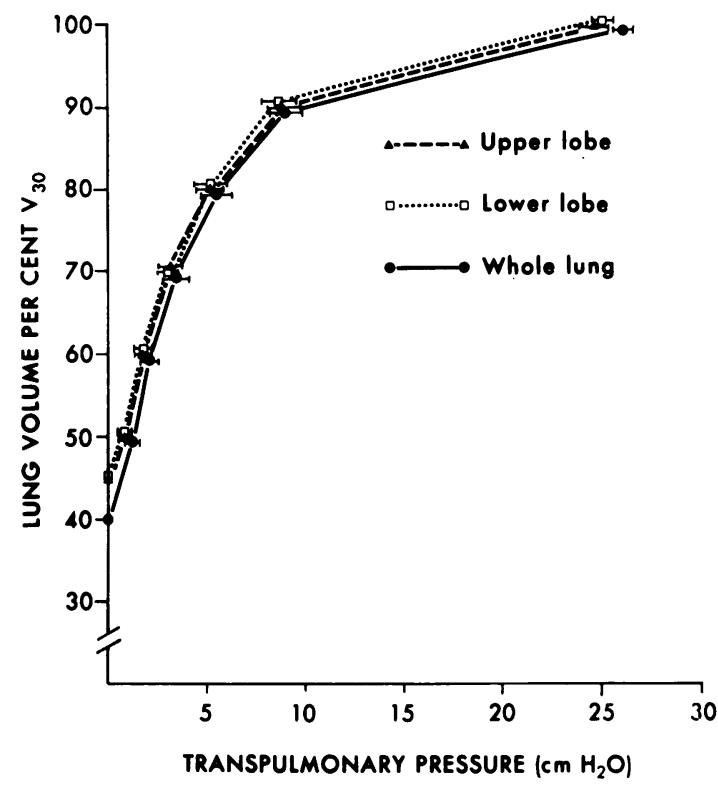

Fig 1 Comparison of pressure-volume curves of the whole lungs and their individual lobes. There is no significant difference between the lobes but the transpulmonary pressure at $50 \% \mathrm{~V}_{30}$ for the whole lungs is significantly greater than for the individual lobes $(p<0.05)$ by paired Student's t test. $V_{30}=$ volume at a transpulmonary pressure $(P L)$ of $30 \mathrm{cmH}_{2} \mathrm{O}$. There was no change in volume on reducing the $P L$ from 30 to about $26 \mathrm{cmH}_{2} O$. Curves are only shown below this pressure. $1 \mathrm{cmH}_{2} \mathrm{O}=$ $0 \cdot 1 \mathrm{kPa}$.

emphysematous lungs, there were no significant differences in $P_{L}$ at any percentage of $V_{30}$, although in the non-emphysematous lungs, there was a trend for the upper lobe $\mathrm{P}-\mathrm{V}$ curve to 


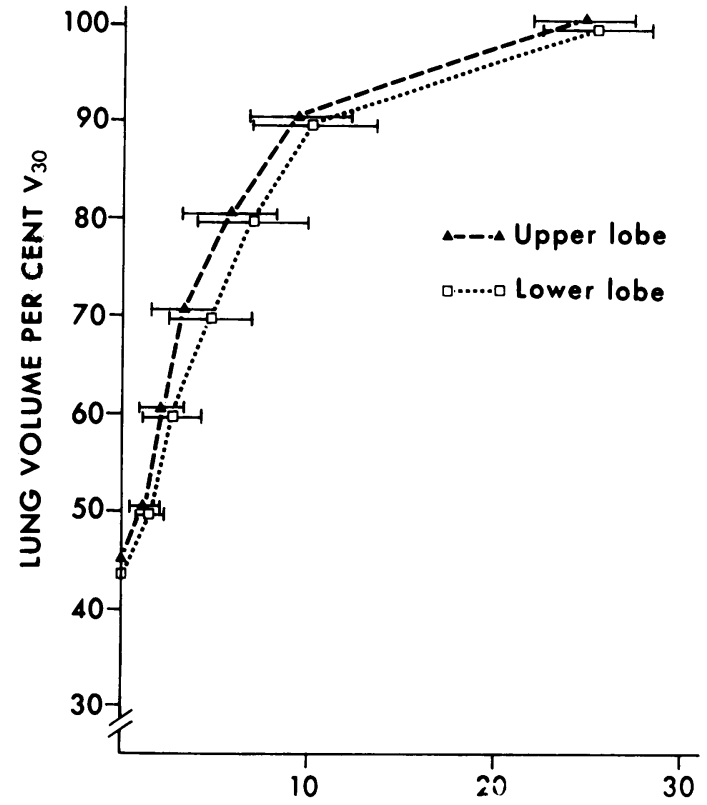

TRANSPULMONARY PRESSURE $\left(\mathrm{cm} \mathrm{H}_{2} \mathrm{O}\right)$

Fig 2 Comparison of the lobar pressure-volume curves in the emphysema-free lungs. There is no significant difference at any lung volume. For abbreviations, see fig 1 .

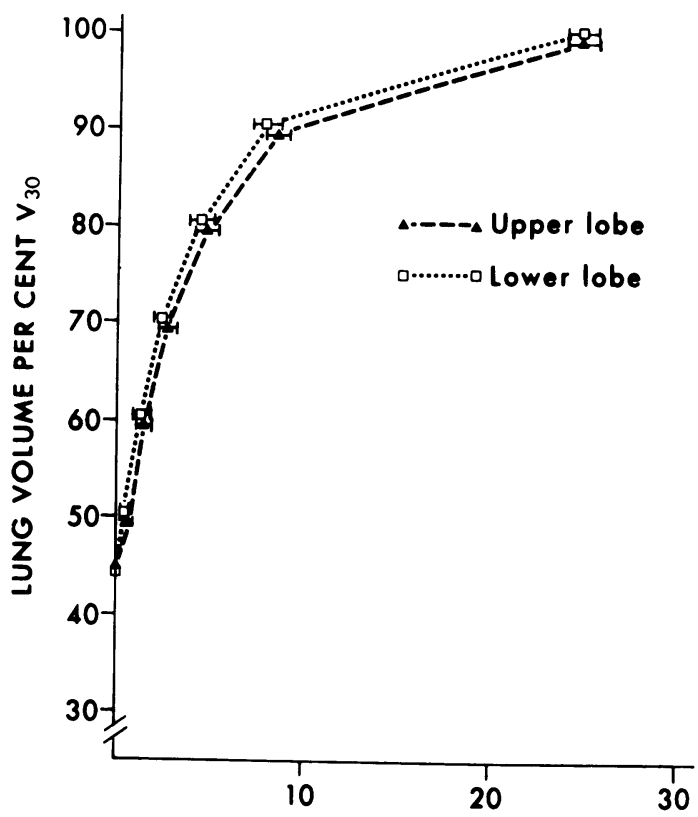

TRANSPULMONARY PRESSURE (cm $\mathrm{H}_{2} \mathrm{O}$ )

Fig 3 Comparison of lobar pressure-volume curves in the emphysematous lungs. There is no significant difference at any lung volume. For abbreviations, see fig 1 .

Table $2 V_{30}$ and $V_{0}$ of the whole lungs and individual lobes

\begin{tabular}{|c|c|c|c|}
\hline & $\begin{array}{l}\text { Upper lobe } V_{30} \\
\left(\text { as } \% \text { whole lung } V_{30}\right)\end{array}$ & $\begin{array}{l}\text { Lower lobe } V_{30} \\
\left(\text { as \% whole lung } V_{30}\right)\end{array}$ & $\begin{array}{l}\text { Upper and lower lobe } V_{30} \\
\left.\text { (as \% whole lung } V_{30}\right)\end{array}$ \\
\hline $\operatorname{Mean} \pm \mathbf{S E}$ & \multicolumn{2}{|c|}{$\begin{array}{l}55 \pm 1 \\
\text { Upper lobe versus lower lobe not significantly different } \\
\text { Paired Student's } t \text { test }\end{array}$} & $117 \pm 2$ \\
\hline Mean $\pm \mathbf{S E}$ & $\begin{array}{l}\text { Upper lobe } V_{0} \% V_{30} \\
45 \pm 3 \\
\text { Upper lobe versus lowe } \\
\text { Upper lobe versus whol } \\
\text { Lower lobe versus wnol } \\
\mathrm{V}_{0}=\text { volume at } 0 \text { transp } \\
\mathrm{V}_{30}=\text { volume at } 30 \mathrm{cmH} \\
1 \mathrm{cmH}_{2} \mathrm{O}=0.1 \mathrm{kPa}\end{array}$ & $\begin{array}{l}\text { Lower lobe } V_{0} \% V_{30} \\
45 \pm 3 \\
\text { ficantly different } \\
5 \\
25 \\
\text { sure } \\
\text { onary pressure }\end{array}$ & $\begin{array}{l}\text { Whole lung } V_{0} \% V_{30} \\
39 \pm 3\end{array}$ \\
\hline
\end{tabular}

exhibit lower PL and in the emphysematous lungs, a trend for the lower lobe to exhibit lower $P_{L}$ at all lung volumes.

On the basis of the paper-mounted whole lung sections, a decision was made in the emphysematous lungs as to which lobe had a greater degree of emphysema. In all but one lung (lung 10, table 1 ), this was the upper lobe. In fig 4 , the P-V curves of the more and less severely involved lobes are compared. Although being virtually identical to fig 3, the change of one pair of lobes has resulted in statistically significant differences in the $P_{L}$ at $60,70,80$, and $90 \% \mathrm{~V}_{30}(\mathrm{P}<0.05)$, with $\mathrm{PL}$ being higher in the more emphysematous lobes.

The lobar $V_{30}$ expressed as a percentage of the 0 whole lung $\mathrm{V}_{30}$ can be seen in table 2. The upper lobes tended to be a little smaller than the lower $\stackrel{\mathbb{D}}{\square}$ lobes but the difference was not statistically sig- $\mathbb{\mathbb { D }}$ nificant. In the emphysematous lungs in which the upper lobes were more severely involved, the ratio of upper to lower lobe $\mathrm{V}_{30}$ tended to be larger than in the emphysema-free lungs $(0.96 \pm$ 


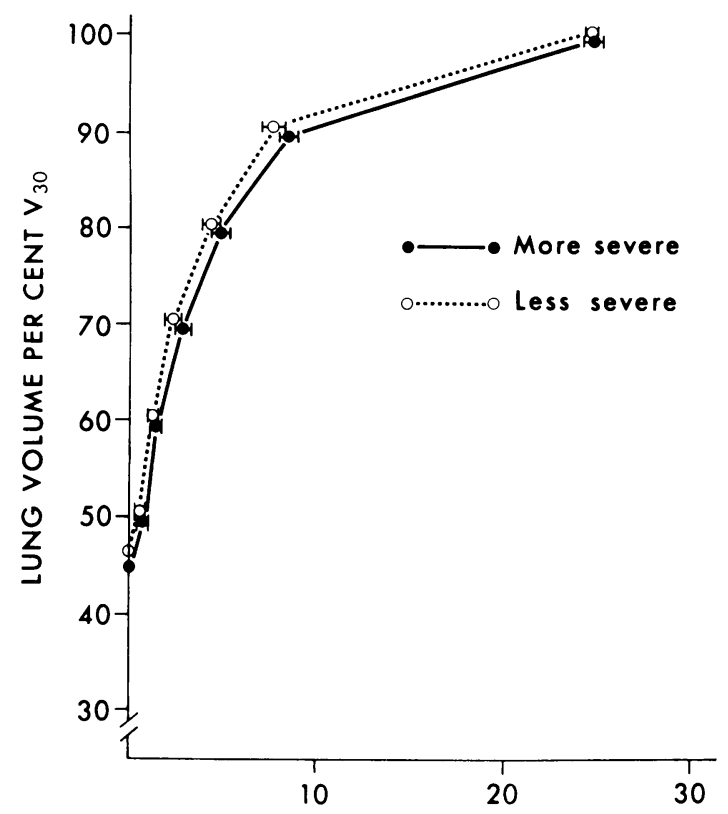

TRANSPULMONARY PRESSURE $\left(\mathrm{cm} \mathrm{H} \mathrm{H}_{2}\right.$ O)

Fig 4 Comparison of the pressure-volume curves of the more and less severely emphysematous lobes of each lung. There are small, but significant differences between the lobes from 60 and 90 per cent $V_{30}$ as tested by Student's paired t test.

Table 3 Mean linear intercepts $(L m)$ in upper and lower lobes fixed at a PL of $25 \mathrm{cmH}_{2} \mathrm{O}$

\begin{tabular}{|c|c|c|}
\hline & $\begin{array}{l}\text { Upper lobe } \\
\operatorname{Lm}(\mathrm{mm})\end{array}$ & $\begin{array}{l}\text { Lower lobe } \\
\operatorname{Lm}(\mathrm{mm})\end{array}$ \\
\hline 1 & $0.66 \pm 0.20$ & $0.37 \pm 0.03$ \\
\hline 2 & $0.21 \pm 0.01$ & $0.21 \pm 0.01$ \\
\hline 3 & $0.34 \pm 0.02$ & $0.41 \pm 0.04$ \\
\hline 4 & $0.25 \pm 0.02$ & $0.25 \pm 0.02$ \\
\hline 5 & $0.31 \pm 0.03$ & $0.31 \pm 0.03$ \\
\hline 6 & $0.29 \pm 0.02$ & $0.29 \pm 0.02$ \\
\hline 7 & $0.31+0.03$ & $0.32 \pm 0.03$ \\
\hline 8 & $0.27 \pm 0.02$ & 0.26 土 0.02 \\
\hline 9 & $0.50 \pm 0.06$ & $0.29 \pm 0.02$ \\
\hline 10 & $0.29 \pm 0.02$ & $0.26 \pm 0.02$ \\
\hline 11 & $0.31 \pm 0.03$ & $0.28 \pm 0.02$ \\
\hline 12 & $0.29 \pm 0.03$ & $0.31 \pm 0.02$ \\
\hline 13 & $0.24 \pm 0.02$ & $0.25 \pm 0.02$ \\
\hline 14 & $0.37 \pm 1.04$ & $0.39 \pm 0.05$ \\
\hline $\begin{array}{l}\text { Mean } \pm S E \\
\text { (all lungs) }\end{array}$ & $0 \cdot 33 \pm 0.03$ & $0.30 \dashv .0 .02$ \\
\hline $\begin{array}{l}\text { Mean } \pm S E \\
\text { (emphysema-free lungs) }\end{array}$ & $0 \cdot 27 \pm 0.01$ & $0 \cdot 27 \pm 0.02$ \\
\hline $\begin{array}{l}\text { Mean } \pm \mathrm{SE} \\
\text { (emphysematous lungs) }\end{array}$ & $0 \cdot 36 \pm 0.04$ & $0.31 \pm 0.02$ \\
\hline $\begin{array}{l}\text { Mean } \pm S E \\
\text { (26 emphysema-free lungs) }\end{array}$ & $0.30 \pm 0.01$ & $0 \cdot 31 \pm 0 \cdot 01$ \\
\hline
\end{tabular}

Upper lobe versus lower lobe not significantly different in any grouppaired Student's $t$ test.
0.06 compared with $0.86 \pm 0.01$, difference not significant). The combined $\mathrm{V}_{30}$ of the upper and lower lobes was greater than the $\mathrm{V}_{30}$ of the whole lung in every case. The $\mathrm{V}_{0} \% \mathrm{~V}_{30}$ of the lobes and whole lungs are shown in table 2 and again, there was no difference between lobes but the whole lungs had a lower $\mathrm{V}_{0} \% \mathrm{~V}_{30}$ than the individual lobes.

There was no significant shift in the $P-V$ curves during the duration of the experiments as judged by comparison of the whole lung $\mathrm{P}-\mathrm{V}$ curves before and after the lobar studies.

The mean linear intercepts $(\mathrm{Lm})$ of the upper and lower lobes of the 14 study lungs are compared in table 3 . There was no statistically significant difference between the lobar $\mathrm{Lm}$ of all the lungs or the emphysematous and non-emphysematous lungs considered separately, although in the emphysematous lungs, the upper lobe $\mathrm{Lm}$ were on the average $16 \%$ larger than the lower lobe $\mathrm{Lm}$.

The $\mathrm{Lm}$ of the upper and lower lobes of the 26 non-emphysematous lungs are also shown in table 3. Again, there was no significant difference between the lobar Lm.

\section{Discussion}

Inhomogeneity of ventilation distribution has been demonstrated in excised $\operatorname{dog}^{8}$ and human lungs. ${ }^{9}$ In the absence of a pleural pressure gradient, this may be because of differences in lobar mechanical properties or inhomogeneity at a sublobar level, or both. In dogs, differences in lobar elastic properties have been clearly defined when the P-V curves have been plotted both as per cent total lung capacity (TLC) ${ }^{2}$ and as $\mathrm{ml} / \mathrm{g}$ of lung. ${ }^{1}$ In addition, inhomogeneity at subsegmental levels has also been demonstrated in dogs. ${ }^{10}$

In the only previously published study of the P-V relationship of human excised lobes, ${ }^{5}$ differences between upper and lower lobes were found when the curves were plotted as per cent $\mathrm{V}_{20}$ (lung volume at $\mathrm{PL}$ of $20 \mathrm{cmH}_{2} \mathrm{O}$ ), but not when plotted as $\mathrm{ml} / \mathrm{g}$ of lung tissue. In human lungs available at necropsy, lobar weights may be misleading as they would be influenced by the mode and position of death of the donor. Indeed, considerable noise appears to have been introduced when Silvers et $a l^{5}$ replotted their data as $\mathrm{ml} / \mathrm{g}$. The results of the present study show no difference in lobar elastic properties when plotted as per cent $\mathrm{V}_{30}$, although there were trends for the upper and lower lobe $\mathrm{P}-\mathrm{V}$ curves to be shifted in opposite directions when the groups of lungs with and without emphysema were considered separately. The $\mathrm{P}-\mathrm{V}$ curves 
of the more severely emphysematous lobes were shifted to the right of the less severely involved lobes. Although in absolute terms the changes were small (the greatest mean difference was 0.8 $\mathrm{cmH}_{2} \mathrm{O}$ occurring at $90 \% \mathrm{~V}_{30}$ ), they were nevertheless significant between 60 and $90 \% \quad V_{30}$ by a Student's paired $t$ test. However, it is possible that plotting the $\mathrm{P}-\mathrm{V}$ data as $\% \mathrm{~V}_{30}$ may conceal real differences in lobar elastic properties. If, for instance, elastic recoil was reduced in emphysematous lungs so that $\mathrm{V}_{30}$ was increased compared to non-emphysematous lungs, expressing the volume as a percentage of $V_{30}$ would obscure these differences. Since there is no reliable information in the literature regarding relative lobar size, it is not possible to plot the lobar $\mathrm{P}-\mathrm{V}$ data as per cent predicted $V_{30}$ which would then reveal the true difference in lobar elastic properties.

This problem could explain the findings of Paré et $a^{4}$ who showed no differences in lobar P-V characteristics in monkeys when plotted as per cent TLC. However, when they obviated this by plotting lobar volumes as $\mathrm{ml} / \mathrm{g}$, differences were apparent. Lobar weights in their experimental animals may have been more reliable than in humans since the animals were killed in the prone position and the lungs drained of blood immediately after death. However, in a small number of excised monkey lungs, Glaister et $a^{8}$ showed an even distribution of ventilation suggesting the absence of differences in lobar elastic behaviour.

We attempted to overcome this problem by measuring the $\mathrm{Lm}$ in the upper and lower lobes fixed at a constant PL. In the emphysema-free lungs, the Lm were identical suggesting that the lobes were equally distended at a $\mathrm{PL}$ of $30 \mathrm{cmH}_{2} \mathrm{O}$ and validating the lack of difference in the upper and lower lobar P-V curves when expressed as per cent $V_{30}$. However, in the emphysematous lungs in which the upper lobes were more severely involved, the upper lobe $\mathrm{Lm}$ tended to be larger than the lower lobe $\mathrm{Lm}$. This may be the result of alveolar wall destruction, overdistension, or both. The ratio of upper to lower lobe $V_{30}$ tended to be higher in the emphysematous lungs suggesting that the upper lobes were overdistended, thus casting doubt on the validity of expressing their $P-V$ characteristics as per cent $V_{30}$. Clearly, if the lobes were increased in volume and the results expressed as per cent of predicted lobar volume, the $\mathrm{P}-\mathrm{V}$ curves of these emphysematous lobes would be shifted to the left. However, even if the lower recoil pressures in the more emphysematous lobes were real and not a consequence of the manner in which the data were expressed, this result would not be out of keeping with some current concepts and experimental evidence.

The expectation that the more emphysematous lobes should have a $\mathrm{P}-\mathrm{V}$ curve shifted to the left is based on the assumption that the lesions of emphysema are more compliant. However, it may be that the alterations in elastic properties of lungs with emphysema lie in the surrounding lung tissue rather than in the emphysematous spaces - that is, two processes, emphysema and alteration in elastic properties, may proceed independently but roughly in parallel. One can speculate that the tobacco smoke, the usual causal agent, produces on the one hand the lesions that the pathologist recognises as emphysema and, on the other hand, produces subtle molecular changes that the physiologist detects as loss of elastic recoil. If this were the case, then the elastic properties might be equally (or more) altered in the lobes with less emphysema. Indeed, our results suggest that this hypothesis may be correct. Other evidence in favour of this hypothesis includes the fact that the surrounding lung tissue (as opposed to the centrilobular emphysematous spaces) has been shown to have lost recoil. ${ }^{12}$ In a lung with uniform loss of lung elastic recoil, it may therefore be expected that the lobe with more centrilobular spaces, which have stiffer walls than the rest of the lung, exhibit less overall loss of recoil. In addition, linear measurements and not alveolar surface area are altered in mildly emphysematous lungs, ${ }^{13}$ suggesting an increase in lung volume difficult to explain on the basis of trivial emphysema, and formalin distended lung volume increases in patients with equivocal emphysema. ${ }^{14}$ The (whole) emphysematous lungs in this study showed loss of elastic recoil compared to the non-emphysematous lungs. However, the emphysematous lungs came from subjects who were on average 10 years older than the subjects with non-emphysematous lungs. Thus, the effect may be caused by age rather than of changes occurring in emphysematous lungs.

The $\mathrm{PL}$ at $50-90 \% \mathrm{~V}_{30}$ of the whole lungs are slightly greater than for the individual lobes, reaching statistical significance for the $\mathrm{PL}$ at $50 \%$ $\mathrm{V}_{30}$. Perhaps, as discussed by Knudson et al, ${ }^{11}$ larger lungs (or whole lungs compared with lobes) exert greater recoil pressures because of the greater amount of lung tissue within them.

The difference between the $V_{30}$ of the lungs and the combined $V_{30}$ of the constituent lobes is $\frac{\Omega}{\Phi}$ difficult to explain. We do not think that this was caused by interlobar collateral ventilation since it ${ }_{2}$ occurred in every lung, regardless of the presence 8 or absence of a complete fissure. Furthermore, any 
ventilation into the degassed clamped lobe at high PL should have been easily visible. Despite close observation, it was never detected. Frank ${ }^{1}$ observed a similar phenomenon in lungs that had been degassed and suggested that simultaneous inflation of both lobes may restrict full inflation of the individual lobes.

This study has documented the lobar elastic properties of 14 excised human lungs. In contrast to a previous study, ${ }^{5}$ elastic properties in emphysema-free lungs were found not to differ significantly between lobes. Expression of the results as per cent $V_{30}$ was validated. However, as this study included only five non-emphysematous lungs and in these, a trend for the $\mathrm{P}-\mathrm{V}$ curves of the upper lobes to lie to the left of those of the lower lobes was demonstrated, it would be desirable to obtain a larger series of normal lungs. This is difficult as only relatively few lungs are suitable for lobar studies. We conclude that the slope of the alveolar plateau in excised human lungs in probably caused by inhomogeneity at a sublobar level or by lobar differences in other than elastic properties. Alternatively, the differences in the elastic properties of the lobes are so subtle that a greater number of lungs are necessary to demonstrate it.

The work was supported by MRC (Canada) Grant no MA 6179 and grants from the Royal Australasian College of Physicians and the Coppleson Postgraduate Medical Institute of the University of Sydney, NSW, Australia.

\section{References}

1 Frank NR. A comparison of static volumepressure relations of excised pulmonary lobes of dogs. J Appl Physiol 1963; 18:274-8.

2 Faridy EE, Kidd R, Milic-Emili J. Topographical distribution of inspired gas in excised lobes of dogs. J Appl Physiol 1967; 22:760-6.

3 D'Angelo E. Local alveolar size and transpulmonary pressure in situ and in isolated lungs. Respir Physiol 1972; 14:251-66.

4 Paré PD, Boucher R, Michaod MC, Hogg JC. Static lung mechanics of intact and excised monkey lungs and lobes J Appl Physiol 1978; 44:54752.

5 Silvers GW, Petty TL, Stanford RE, Filley GW. The elastic properties of lobes of excised human lungs. Am Rev Respir Dis 1979; 120:207-9.

6 Thurlbeck WM, Dunnill MS, Hartung W et al. A comparison of three methods of measuring emphysema. Hum Pathol 1970; 1:215-26.

7 Dunnill MS. Quantitative methods in the study of pulmonary pathology. Thorax 1962; 17:320-8.

8 Glaister DH, Schroter RC, Sudlow MF, MilicEmili J. Transpulmonary pressure gradient and ventilation distribution in excised lungs. Respir Physiol 1973; 17:365-85.

9 Silvers GW, Fine R, Paul GW, Stanford RE, Petty TL, Filley GF. Effect of increased static lung recoil on ventilation distribution in excised human lungs. Am Rev Respir Dis 1977; 115:43542.

10 Engel LA, Utz G, Wood LDH, Macklem PT. Ventilation distribution in anatomical lung units. J Appl Physiol 1974; 37:194-200.

11 Knudson RJ, Clark DF, Kennedy TC, Knudson DE. Effect of aging alone on mechanical properties of the normal adult human lung. $J$ Appl Physiol 1977; 43:1054-62.

12 Hogg JC, Nepszy SJ, Macklem PT, Thurlbeck WM. Elastic properties of the centrilobular emphysematous space. J Clin Invest 1969; 48:130612.

13 Thurlbeck WM. Internal surface area and other measurements in emphysema. Thorax 1967; 22: 483-96.

14 Thurlbeck WM. Lung volumes at necropsy. Thorax 1981; in press. 